\title{
Discovery of Sympatric Dwarf Lemur Species in the High-Altitude Rain Forest of Tsinjoarivo, Eastern Madagascar: Implications for Biogeography and Conservation
}

\author{
Marina B. Blanco ${ }^{a} \quad$ Laurie R. Godfrey ${ }^{a}$ \\ Mamihasimbola Rakotondratsima ${ }^{b}$ Vololonirina Rahalinarivo ${ }^{b}$ \\ Karen E. Samonds ${ }^{c}$ Jean-Luc Raharison ${ }^{d}$ Mitchell T. Irwin ${ }^{c}$ \\ a Department of Anthropology, University of Massachusetts, Amherst, Mass., USA; \\ ${ }^{\text {b}}$ Département de Paléontologie et d'Anthropologie Biologique, Université \\ d'Antananarivo, Antananarivo, Madagascar; ${ }^{C}$ Redpath Museum, McGill University, \\ Montreal, Que., Canada; ${ }^{d}$ Département de Biologie Animale, Écologie-Environnement, \\ Université d'Antananarivo, Antananarivo, Madagascar
}

\section{Key Words}

Morphometrics $\cdot$ Dental morphology $\cdot$ Cheirogaleus $\cdot$ Cheirogaleidae $\cdot$ Dwarf lemur $\cdot$ Sympatry

\begin{abstract}
The number of species within the Malagasy lemur genus Cheirogaleus is currently under debate. Museum collections are spotty, and field work, supplemented by morphometric and genetic analysis, is essential for documenting geographic distributions, ecological characteristics and species boundaries. We report here field evidence for 2 dwarf lemur species at Tsinjoarivo, an eastern-central high-altitude rain forest: one, from a forest fragment, displaying coat and dental characteristics similar to $C$. sibreei (previously described only from museum specimens) and the other, from the continuous forest, resembling individuals of Cheirogaleus found today at Ranomafana National Park, further to the south. This study represents the first confirmation of a living population of grey-fawn, C.-sibreei-like, dwarf lemurs in Madagascar.
\end{abstract}

Copyright $\odot 2008$ S. Karger AG, Basel

\section{Introduction}

The lemurs of Madagascar have been subjects of systematic study for over 100 years [Milne-Edwards and Grandidier, 1875; Mittermeier et al., 2006]. However, the last 25 years have seen a dramatic increase in the number of recognized species, from

\begin{tabular}{ll}
\hline KARGER & @ 2008 S. Karger AG, Basel \\
Fax +4161306 1234 & \\
$\begin{array}{l}\text { E-Mail karger@karger.ch } \\
\text { www.karger.com }\end{array}$ & $\begin{array}{l}\text { Accessible online at: } \\
\text { www.karger.com/fpr }\end{array}$
\end{tabular}

Marina B. Blanco

Department of Anthropology, 240 Hicks Way

University of Massachusetts, Amherst, MA 01003 (USA)

Tel. +1 413545 3802, Fax +1 4135459494

E-Mail mbblanco@anthro.umass.edu 
36 in 1982 to over 80 today [Tattersall, 2007]. While this expansion has not gone uncontested [Tattersall, 2007], at least some of it reflects our increasing knowledge of previously unrecognized diversity. In particular, there is mounting evidence that past classifications severely underestimated the diversity of the smaller nocturnal lemurs. Several nocturnal genera have been shown to contain genetically and ecologically distinct species which are difficult to distinguish visually and often exist in sympatry [Rasoloarison et al., 2000; Hapke et al., 2005].

The nocturnal genus Cheirogaleus (dwarf lemurs) was long thought to contain only 2 species: the eastern C. major (with 2 subspecies, major and crossleyi) and the western and southern C. medius [e.g. Petter et al., 1977]. Groves [2000], using museum specimens, expanded this diversity to 7. He recognized 2 morphs (C. adipicaudatus in southern spiny forests and $C$. medius in western dry forests) within the ' $C$. medius' group. A 'C. major' group was erected to include $C$. major from the eastern rain forests, $C$. crossleyi from the margins of the central plateau, the resurrected $C$. sibreei from Ankeramadinika (east of Antananarivo) as well as Ampasindava Bay in north-western Madagascar and 2 new species: C. ravus and C. minusculus. Unfortunately, because this study was based on few specimens (usually with inexact provenience), it is difficult to evaluate the validity of these newly recognized forms and harder still to contextualize them geographically.

Subsequently, Groeneveld et al. [2008a, b] undertook a molecular and morphometric analysis of museum specimens, supplemented by field data from selected localities. Largely on the basis of molecular data, they rejected many of Groves' interpretations. As with many recent taxonomic treatments, however, genetic sampling is outpacing on-the-ground surveys; we know little about species boundaries, or geographic and/or clinal variation within taxa. Field work is an essential complement to genetic studies in efforts to evaluate the taxonomic revisions that now abound.

One of the driving factors behind Madagascar's high species diversity and local endemism is its topography. The island can be viewed as a ring of coastal lowlands (narrowest along the east) encircling a central high plateau. The plateau is highest in the east (giving rise to several mountain chains and the 'eastern escarpment' running north-south) and slopes more gradually towards the sea in the west.

Among these regions, Madagascar's central plateau remains one of the island's most persistent biogeographic mysteries. Forests in Madagascar's lowlands have been reduced to fragmented remnants of their former extents [Green and Sussman, 1990; Dufils, 2003]; however, the remnant vegetation is generally rain forest (east and north), deciduous forest (west) or open spiny forest (south), and there is little doubt that this vegetation was formerly widespread. The high plateau contains almost no remaining forest, being dominated by grassland and human settlement; this has hindered our understanding of the region's past vegetation, as well as biogeographic patterns across the island. Early researchers were somewhat ambiguous in reconstructing that original cover; some [MacPhee et al., 1985; Burney, 1997] interpret their work as implying continuous forest while others [Lowry II et al., 1997] infer a mosaic of woodland and grassland. Palynological data, coupled with data on extant lemur distributions, and the locomotor ecology of extinct plateau lemurs, suggest at least some forest cover [Burney, 1997; Godfrey et al., 1997; Mittermeier et al., 2006].

One locality that may preserve elements of a plateau fauna is Tsinjoarivo, located $80 \mathrm{~km}$ south-south-east of Antananarivo, just west of the eastern escarpment (fig. 1). Tsinjoarivo contains unprotected central domain mid-altitude rain forest 


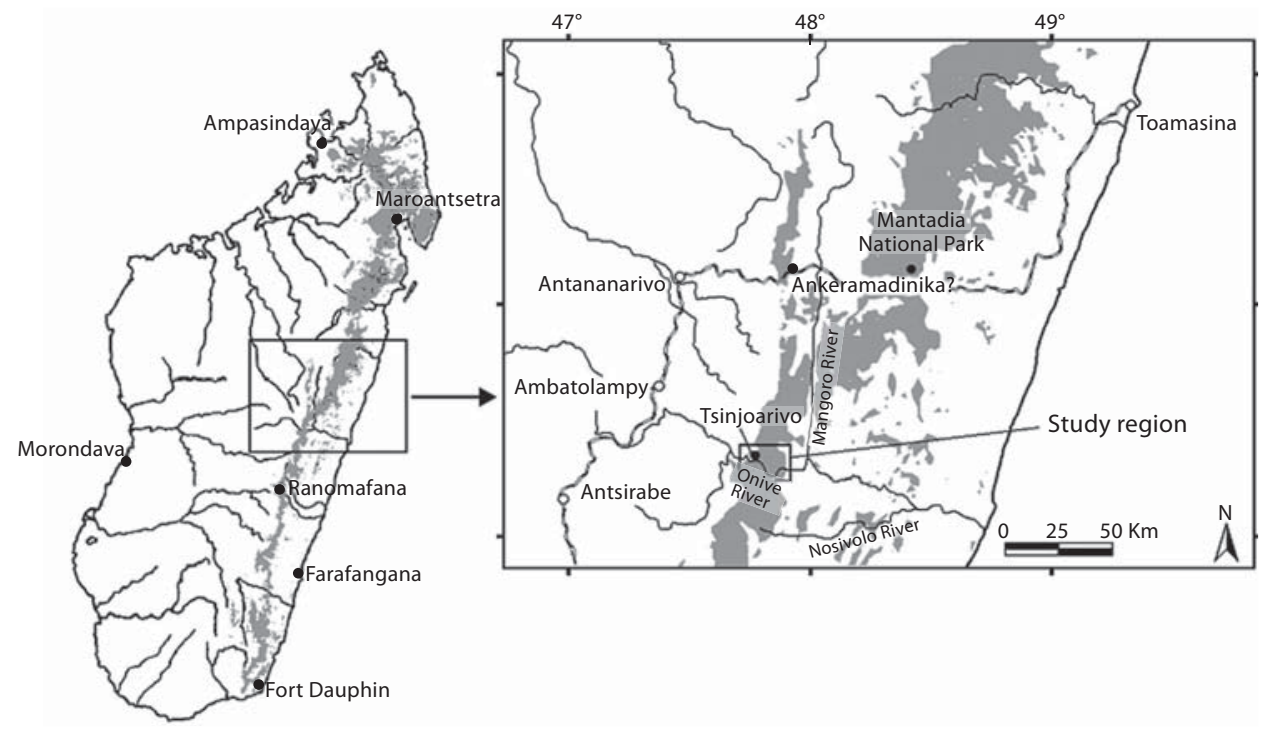

Fig. 1. Map of Tsinjoarivo and other localities mentioned in the text, including the approximate location of Ankeramadinika [Jenkins and Carleton, 2005].

[Koechlin et al., 1974], within the eastern rain forest corridor including Ranomafana (150 km south-south-west) and Mantadia (100 km north-east) National Parks. Tsinjoarivo Forest's western half (1,300-1,675 m altitude) is topographically continuous with the plateau, and has been fragmented and degraded by settlers from this region. The eastern half is slightly lower $(1,200-1,600 \mathrm{~m})$, but because its eastern boundary is coincident with the steep escarpment, it is less accessible and remains minimally disturbed [Irwin, 2006].

Tsinjoarivo is biogeographically interesting due to three factors, which make it a prime location for possibly preserving relict species. First, it is part of a relatively small forest block isolated between two major river barriers (Onive to the south and Mangoro to the east) which constitute range boundaries for several lemurs [Mittermeier et al., 2006]. Second, it falls at the upper end of the elevation range for eastern rain forests; while other forests of similar altitude remain (e.g. Andringitra, Marojejy, Tsaratanana), each is isolated by intervening lower-altitude forests. Third, it is topographically continuous with the central plateau and not separated by major rivers.

Biological inventories at Tsinjoarivo began in 1929 with an ornithological expedition [Rand, 1936]. Rakotondraparany [1997] and Goodman [Goodman and Schütz, 1999; Goodman et al., 2000a] conducted brief biological inventories, and, in the year 2000 , Irwin et al. launched an ecological study of Tsinjoarivo's sifakas and other primates. The limited research to date has revealed a fauna containing a mixture of lower-altitude (eastern rain forest) and higher-altitude (central plateau) species, in- 
cluding the first reliable record of a syntopic occurrence of the lowland and highland streaked tenrecs (Hemicentetes semispinosus and H. nigriceps) [Goodman et al., 2000b].

In this paper, we present the first detailed characterization of dwarf lemurs (Cheirogaleus) at two sites within Tsinjoarivo Forest. Past surveys (with no capture) have ascribed dwarf lemurs at both sites to C. major [Randrianambinina et al., 1995, in Rakotondraparany, 1997; Goodman and Schütz, 1999], but a proper diagnosis of small, nocturnal primates is difficult without close observation. We present evidence for the existence of 2 sympatric species at Tsinjoarivo and discuss their taxonomic identity.

\section{Materials and Methods}

Two research camps were established by M.T.I. at Tsinjoarivo in 2001 (fig. 1): Mahatsinjo $\left(19^{\circ} 40^{\prime} 56^{\prime \prime} \mathrm{S}, 47^{\circ} 45^{\prime} 28^{\prime \prime} \mathrm{E}, 1,590 \mathrm{~m}\right)$ contains hill and ridge top forest fragments in the western, fragmented forest; Vatateza $\left(19^{\circ} 43^{\prime} 15^{\prime \prime} \mathrm{S}, 47^{\circ} 51^{\prime} 25^{\prime \prime} \mathrm{E}, 1,396 \mathrm{~m}\right), 12 \mathrm{~km}$ to the south-east, is within continuous forest. In November-December 2006, and November 2007 to January 2008, M.B.B., M.R., V.R. and local assistants trapped lemurs within a 228-ha forest fragment at Andasivodihazo (in the Mahatsinjo region) and continuous rain forest at Vatateza. To document the presence of nocturnal lemurs, we conducted nocturnal censuses $(0.5-1 \mathrm{~km} / \mathrm{h})$, between 19:00 and 23:00 $\mathrm{h}$, following main trails near both campsites. Trap locations were sometimes changed according to census sightings. Vatateza traps were set up to $1 \mathrm{~km}$ from the nearest forest edge, and Andasivodihazo traps were set up to approximately $200 \mathrm{~m}$ (the maximum available distance) from the edge. Fifteen Tomahawk traps were set daily along preexisting trails at a minimum distance of $25 \mathrm{~m}$ and between 4 and $10 \mathrm{~m}$ high. Traps were baited starting at 16:00 $\mathrm{h}$ with fermented banana, and checked between 4:00 and 7:00 $\mathrm{h}$ the following morning. Non-primate captures were recorded and immediately released; all cheirogaleids were brought to the campsite for processing. Individuals were anaesthetized using Telazol ${ }^{\circledR}(7-10 \mathrm{mg} / \mathrm{kg})$ and marked with Avid microchips. Small $\left(1-2 \mathrm{~mm}^{2}\right)$ tissue biopsies from ears were taken for genetic analysis, and mandibular dental moulds were made. Body mass and morphometric data were gathered using spring scales, callipers and tape. Pelage and genital characteristics were also recorded. Individuals were monitored throughout recovery from anaesthesia and released at the capture site at dusk.

Comparative morphometric data and mandibular dental moulds were collected for 15 Cheirogaleus trapped by M.B.B., M.R. and V.R. at Talatakely, within Ranomafana National Park (RNP) between October and December of 2005 and 2006, and October 2007. A maxillary dental mould was made by K.E.S. for the single individual from Tsinjoarivo whose skeleton was available: UADBA-TFFP-001 was an adult female who was injured in a fire at Mahatsinjo, and subsequently died. The specimen is considered adult based on complete dental eruption and epiphyseal fusion of long bones.

Comparative data were collected on maxillary teeth moulded by L.R.G. from museum specimens [C. major $(\mathrm{n}=5$, from Farafangana in south-eastern Madagascar to Maroantsetra and Ampasimbe in north-eastern Madagascar), C. medius ( $\mathrm{n}=3$, from the region of Morondava, western Madagascar), C. crossleyi $(\mathrm{n}=3$, from the region of Montagne d'Ambre in northwestern Madagascar to Ampitambe and Mahavelona, or Foulpointe in eastern Madagascar) and C. sibreei ( $\mathrm{n}=1$, from Ampasindava Bay, north-western Madagascar); note that destructive sampling, including dental moulding, of the type C. sibreei from Ankeramadinika was prohibited]. A list of specimen numbers (with Groves' taxonomic attributions, when applicable) is available from L.R.G.

In order to digitally capture dental surfaces, high-quality plaster casts (Fujirock, Leuven, Belgium) were made from moulds and scanned with a needle-point piezo scanner (MDX-15, Roland) at $0.05 \mathrm{~mm}$ resolution. Three-dimensional point files were exported into GIS software 

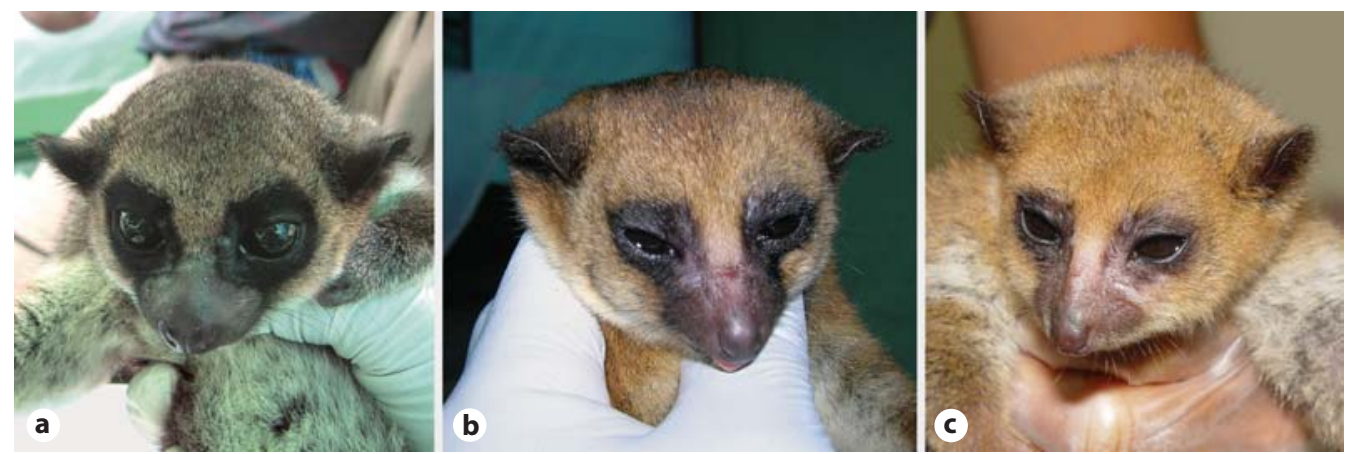

Fig. 2. Live-trapped Cheirogaleus from Andasivodihazo (a), Vatateza (b) and Ranomafana (Talatakely, c).

(MFWorks 3.0, Keigan Systems, London, Canada), and digital elevation models (DEMs) were obtained by interpolating surfaces onto coordinate data. Longitudinal and transverse crests of $\mathrm{M}^{2}$ and $\mathrm{M}_{2}$ were isolated using routine tools in MFWorks, and occlusal 2- and 3-dimensional areas as well as 2- and 3-dimensional transverse and longitudinal crest lengths were calculated for each tooth. The length of each tooth row $\left(\mathrm{P}_{4}-\mathrm{M}_{3}\right)$ was measured digitally.

One-way analysis of variance (ANOVA) with Tukey's post hoc tests of honestly significant differences (HSD) was used to compare traits among sites. Dental analyses included only individuals with fully erupted adult dentition, and morphometric analyses included only fully adult individuals. Discriminant function analysis (DFA) was used to characterize samples at different sites based on morphometric and mandibular dental variables, and to discriminate species based on $\mathrm{M}^{2}$ morphology. Tests were performed using SPSS version 14.0 .

\section{Results}

Four nocturnal lemur genera (Avahi, Microcebus, Lepilemur and Cheirogaleus) were sighted in both the continuous forest (Vatateza) and the fragment (Andasivodihazo) during censuses. Tomahawk traps captured mainly Cheirogaleus, but on rare occasions, we captured other primates (1 Lepilemur, 3 Microcebus). We captured 18 Cheirogaleus at Vatateza (5 subadults, 13 adults) and 20 at Andasivodihazo (5 subadults, 15 adults).

\section{Morphological Description: Pelage}

Cheirogaleus at Andasivodihazo have grey-fawn fur on the back and cap, with or without a darker dorsal median line, and light grey or creamy fur (with whitish tips and darker roots) on the belly (fig. 2a). The lighter colouration of the belly continues cranially as bands extending onto the sides of the neck, but not the back. The orbits are surrounded by distinct, broad and very black eye rings. There may be thin extensions of this black colouration (or none at all) delineating the sides of the muzzle, but the dominant colour of the muzzle is only slightly greyer than the dorsal fur and very uniform, and the rhinarium tends to be pink. The ear pinnae are dark with sparse hair on their inner and outer surfaces. The hands and feet are pink ventrally 

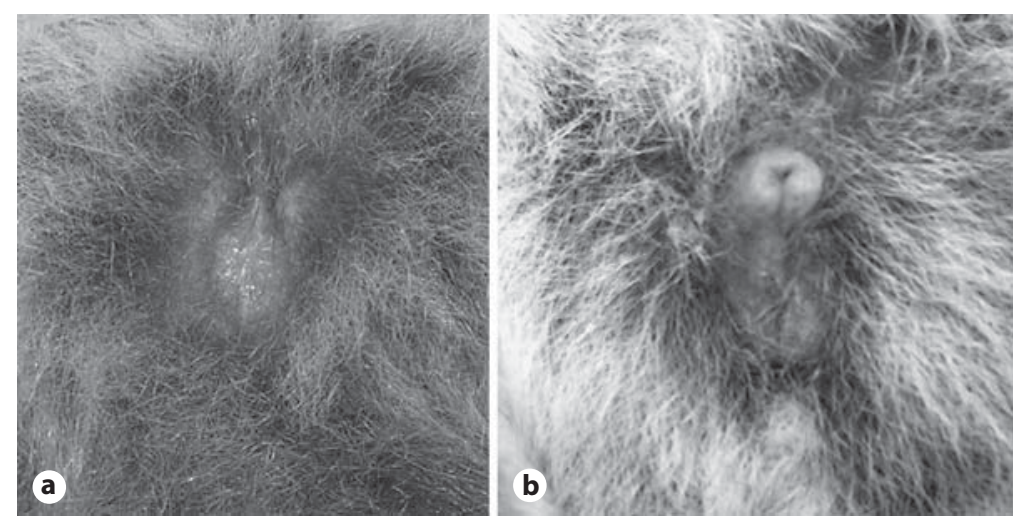

Fig. 3. External genitalia of adult females from Vatateza (a) and Andasivodihazo (b), photographed in November 2007.

and grey-brown dorsally. The dominant colour of the dorsal fur closely matches that of specimens that Groves [2000] attributed to C. sibreei.

Cheirogaleus at Vatateza (fig. 2b) have reddish brown dorsal fur with no visible median line, and light brown ventral fur, similar to individuals from RNP (fig. 2c). The light brown colouration of the ventral fur may extend cranially onto the sides of the neck, but it narrows rapidly. The dorsal fur is distinctly browner than that of Andasivodihazo individuals. The eye 'rings' are noticeably thinner and less defined, continuing broadly onto the sides of the snout towards its tip. A narrow stripe of light brown fur extends from the region between the eyes to the rhinarium, giving the impression (with the darker fur on both sides of the snout) of a narrow, pointy nose. This stripe is somewhat variable in colour; in some individuals it is distinctly lighter than the rest of the face and cap, while in others it closely matches the cap. The moist, naked rhinarium is brown. The ear pinnae have sparse hair on their inner and outer surfaces. The hands and feet are pink ventrally with reddish brown dorsal fur.

\section{Morphological Description: Female Genitalia}

We observed the external morphology of the clitoris in 11 females from Vatateza and 9 from Andasivodihazo captured throughout the study period (fig. 3). Subadults and adults from Vatateza displayed a morphology similar to all RNP females: anterior to the vagina (which remains imperforated except during oestrus and parturition) a narrow and thin clitoral shaft culminates in a rather inconspicuous glans clitoridis (sensu Drea and Weil [2008]). In contrast, 8 of 9 females (both reproductive and non-reproductive, including 1 subadult) at Andasivodihazo had a masculinized, enlarged clitoral shaft with central cleft from base to tip and bulbous glans. A similar clitoral hypertrophication and 'masculinization' have been reported in other lemur species (e.g. ring-tailed lemurs [Drea and Weil, 2008]; red-fronted lemurs [Ostner et al., 2003]; Cheirogaleus medius [Treatman-Clark, 2006]). Only 1 female from Andasivodihazo displayed a clitoral morphology similar to Vatateza females; the reason for this variation is presently unclear. 
Table 1. Comparative morphometrics of Cheirogaleus from Tsinjoarivo (Vatateza and Andasivodihazo) and Ranomafana (Talatakely)

\begin{tabular}{|c|c|c|c|}
\hline & $\begin{array}{l}\text { Ranomafana } \\
(\mathrm{n}=15)\end{array}$ & $\begin{array}{l}\text { Vatateza } \\
(\mathrm{n}=13)\end{array}$ & $\begin{array}{l}\text { Andasivodihazo } \\
(\mathrm{n}=15)\end{array}$ \\
\hline \multicolumn{4}{|l|}{ Body mass, g } \\
\hline Mean $\pm S D$ & $365.9 \pm 43.9$ & $317.9 \pm 60.8$ & $272.1 \pm 35.6$ \\
\hline Min.-max. & $311.5-471.5$ & $255.5-456$ & $219-359.5$ \\
\hline \multicolumn{4}{|c|}{ Crown-tail base length, $\mathrm{cm}$} \\
\hline Mean $\pm \mathrm{SD}$ & $24.6 \pm 1.3$ & $24.0 \pm 1.3$ & $21.8 \pm 0.9$ \\
\hline Min.-max. & $22.8-27$ & $22.5-27$ & $20.5-23.5$ \\
\hline \multicolumn{4}{|l|}{ Tail length, cm } \\
\hline Mean \pm SD & $27.7 \pm 1.3$ & $25.4 \pm 1.1$ & $23.5 \pm 1.3$ \\
\hline Min.-max. & $25.5-30$ & $23.5-27$ & $22-26.5$ \\
\hline \multicolumn{4}{|c|}{ Hindlimb length, $\mathrm{cm}$} \\
\hline Mean $\pm S D$ & $17.0 \pm 1.2$ & $15.7 \pm 0.3$ & $15.0 \pm 1.1$ \\
\hline Min.-max. & $15.2-20$ & $15-16$ & $13.6-18$ \\
\hline \multicolumn{4}{|c|}{ Hindfoot length, mm } \\
\hline Mean \pm SD & $53.0 \pm 3.4$ & $49.9 \pm 1.9$ & $46.8 \pm 2.0$ \\
\hline Min.-max. & $44.7-58.7$ & $47.3-53.6$ & $44.6-51.9$ \\
\hline \multicolumn{4}{|c|}{ Forefoot length, mm } \\
\hline Mean \pm SD & $35.2 \pm 2.2$ & $33.3 \pm 1.6$ & $32.0 \pm 1.2$ \\
\hline Min.-max. & $30-38.3$ & $29.2-35.1$ & $29.7-34.1$ \\
\hline \multicolumn{4}{|l|}{ Head length, mm } \\
\hline Mean $\pm S D$ & $58.6 \pm 1.5$ & $56.5 \pm 1.0$ & $54.8 \pm 1.0$ \\
\hline Min.-max. & $56.6-61.3$ & $54.1-57.6$ & $53.2-57.3$ \\
\hline \multicolumn{4}{|l|}{ Head width, mm } \\
\hline Mean \pm SD & $35.6 \pm 1.8$ & $33.2 \pm 0.8$ & $32.8 \pm 1.7$ \\
\hline Min.-max. & $31.9-39$ & $32-34.7$ & $30.2-35.7$ \\
\hline \multicolumn{4}{|l|}{ Snout length, mm } \\
\hline Mean $\pm S D$ & $16.7 \pm 1.0$ & $17.0 \pm 1.0$ & $15.2 \pm 1.2$ \\
\hline Min.-max. & $14.9-19.1$ & $15.7-19.2$ & $12.1-16.8$ \\
\hline \multicolumn{4}{|l|}{ Ear length, mm } \\
\hline Mean $\pm S D$ & $19.1 \pm 4.1$ & $21.8 \pm 1.4$ & $22.8 \pm 1.8$ \\
\hline Min.-max. & $11.9-26.5$ & $18.9-23.5$ & $19.1-25.2$ \\
\hline \multicolumn{4}{|l|}{ Ear width, mm } \\
\hline Mean \pm SD & $13.8 \pm 1.4$ & $10.8 \pm 0.7$ & $12.8 \pm 1.0$ \\
\hline Min.-max. & $11-16.1$ & $9.9-12.3$ & $10.3-14.6$ \\
\hline
\end{tabular}

Measurements taken with flexible tape: tail length = ventrally, from the base of the anus to the distal end of the last caudal vertebra; crown-tail base = dorsally, from the forehead to the cranial margin of the first caudal vertebra; hindlimb length = from the femoral head to the distal end of the 4th digit, measured with the limb and foot extended. Measurements taken with callipers: hindfoot length = maximum length of the foot from the calcaneal robusticity to the distal end of the 4th digit; forefoot length = maximum length including the palm from its proximal margin to the distal end of the 4th digit; head length = maximum length of the head from the most projecting margin of the rhinarium to the back of the braincase; head width = maximum bizygomatic breadth; snout length = maximum length from the most projecting margin of the rhinarium to a virtual line projected transversely across the base of the orbits; ear length = maximum length between the base of the tragus and the tip of the pinna; ear width $=$ maximum aperture between the basal end of the tragus and the lateral edge of the pinna. 
Table 2. ANOVA of morphometric measurements, with Tukey's post hoc tests of significance of differences between populations

\begin{tabular}{lclll}
\hline Variable & p values & $\mathrm{R}-\mathrm{V}$ & $\mathrm{R}-\mathrm{A}$ & $\mathrm{V}-\mathrm{A}$ \\
\hline Body mass & $<0.001$ & $*$ & $* * *$ & $*$ \\
Crown-tail base & $<0.001$ & $\mathrm{NS}$ & $* * *$ & $* * *$ \\
Tail length & $<0.001$ & $* * *$ & $* * *$ & $* * *$ \\
Hindlimb length & $<0.001$ & $* *$ & $* * *$ & $\mathrm{NS}$ \\
Hindfoot length & $<0.001$ & $* *$ & $* * *$ & $* *$ \\
Forefoot length & $<0.001$ & $*$ & $* * *$ & $\mathrm{NS}$ \\
Head length & $<0.001$ & $* * *$ & $* * *$ & $* *$ \\
Head width & $<0.001$ & $* * *$ & $* * *$ & $\mathrm{NS}$ \\
Snout length & $<0.001$ & $\mathrm{NS}$ & $* *$ & $* * *$ \\
Ear length & 0.002 & $*$ & $* *$ & $\mathrm{NS}$ \\
Ear width & $<0.001$ & $* * *$ & $*$ & $* * *$ \\
\hline
\end{tabular}

$\mathrm{R}=$ Ranomafana $\mathrm{A}=$ Andasivodihazo; $\mathrm{V}=$ Vatateza. ${ }^{*} \mathrm{p}<$ $0.05,{ }^{* *} \mathrm{p}<0.01,{ }^{* * *} \mathrm{p}<0.001 ; \mathrm{NS}=$ non-significant.

Table 3. Structure matrix (or correlations) of the DFA of morphometric variables

\begin{tabular}{lcc}
\hline Variable & Function 1 & Function 2 \\
\hline Tail length & 0.669 & -0.217 \\
Head length & 0.613 & -0.171 \\
Hindlimb length & 0.402 & -0.049 \\
Head width & 0.392 & 0.082 \\
Ear length & -0.272 & -0.003 \\
Interpupil distance & 0.156 & -0.075 \\
Ear width & 0.292 & 0.703 \\
Crown-tail base & 0.426 & -0.458 \\
Snout length & 0.213 & -0.434 \\
\hline
\end{tabular}

\section{Morphometric Analysis}

Table 1 provides morphometric data for the 28 adults captured at Tsinjoarivo and 15 from RNP. For most variables, Andasivodihazo individuals have smaller means than those from Vatateza, which in turn fall below those from RNP (table 2). ANOVAs with Tukey's post hoc tests of HSD show the greatest differences between RNP and Andasivodihazo, followed by those between RNP and Vatateza. For approximately $60 \%$ of variables, the 2 Tsinjoarivo samples differ significantly.

A DFA based on morphometrics correctly classified $100 \%$ of individuals from all 3 locations (fig. 4); axes 1 and 2 were statistically significant $(p<0.001)$. The first function separated RNP individuals (positive scores) from Tsinjoarivo individuals (with Andasivodihazo individuals displaying the most negative scores; fig. 4). Positive scores on function 1 described individuals with relatively long tails, longer bod- 


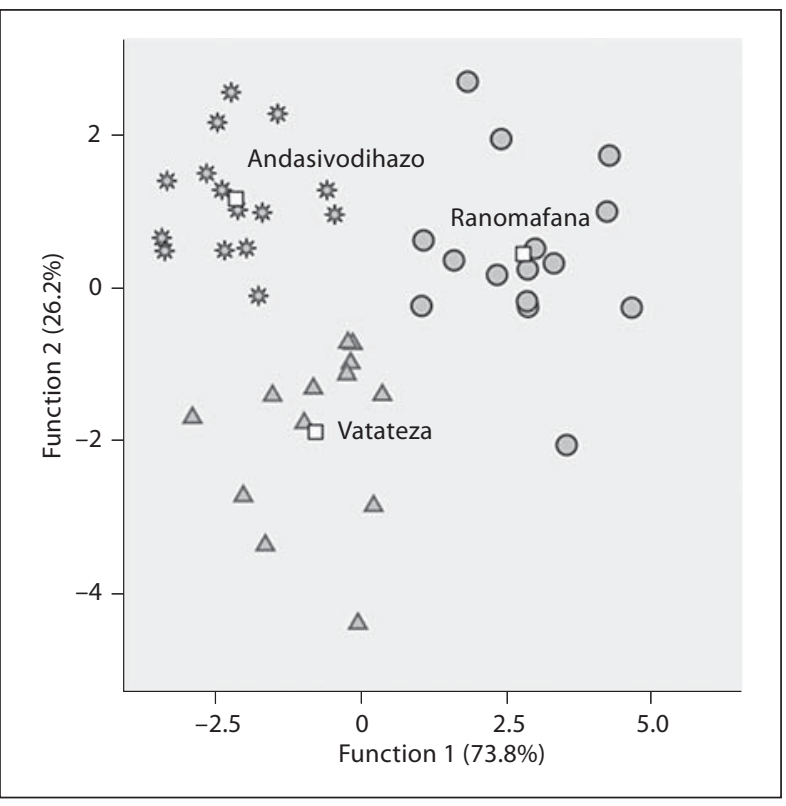

Fig. 4. DFA of morphometric variables: tail length, crown-to-tail-base length, hindlimb length, head length, head width, snout length, ear length, ear width and interpupil distance.

ies (crown-tail), and longer and wider heads, but relatively short ears. On the second function, Vatateza individuals differed from Andasivodihazo individuals in having relatively narrower ear pinnae, longer snouts and longer bodies (table 3).

\section{Dental Analysis}

In agreement with our morphometric analysis, $\mathrm{M}_{2}$ is smaller at Tsinjoarivo (particularly Andasivodihazo) than at RNP (fig. 5, table 4). The $\mathrm{P}_{4} \mathrm{~s}$ are also smallest in individuals from Andasivodihazo. Occlusal measurements show the same pattern (table 4, 5). ANOVAs showed significant differences in tooth row length $\left(\mathrm{P}_{4}-\mathrm{M}_{3}\right), \mathrm{M}_{2}$ occlusal areas (2- and 3-dimensional) and transverse crest lengths (2- and 3-dimensional). Tukey's post hoc tests of HSD confirmed the greatest differences between Andasivodihazo and RNP samples; only 2 variables differ significantly between Andasivodihazo and Vatateza (table 5).

A DFA of $\mathrm{M}_{2}$ occlusal variables demonstrates size and shape differences. The 3 samples were distinguished with $100 \%$ classification success on the basis of 2 significant functions (function $1, \mathrm{p} \leq 0.001$; function $2, \mathrm{p}=0.005$ ). The first function separates samples from RNP (positive scores) and Tsinjoarivo (negative scores). The variables correlating most strongly with scores on this axis were 3- and 2-dimensional longitudinal crest length $(\mathrm{r}=0.56$ and $\mathrm{r}=0.39), 3$ - and 2-dimensional transverse crest length $(r=0.53$ and $r=0.46)$, and the square root of 3-dimensional $\mathrm{M}_{2}$ occlusal area $(\mathrm{r}=0.37)$. The second function polarizes individuals from Andasivodihazo (positive scores) and Vatateza (negative scores). The former have smaller occlusal surfaces but longer mesiodistal crests (fig. 6). 


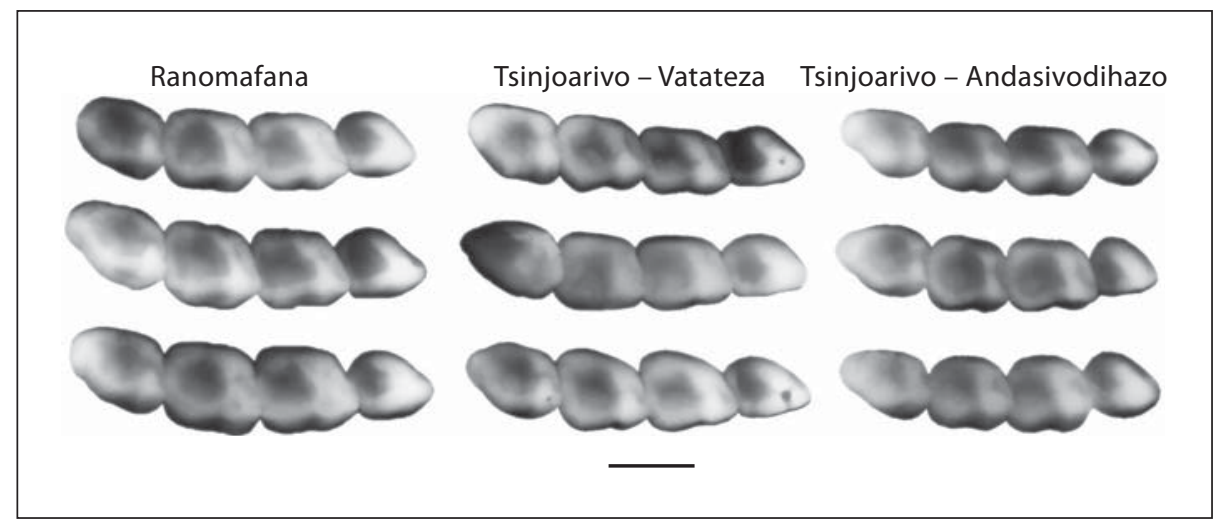

Fig. 5. DEMs of lower right tooth row $\left(\mathrm{P}_{4}-\mathrm{M}_{3}\right)$ of Cheirogaleus spp. from Tsinjoarivo and Ranomafana. Mesial to right; scale bar $=3 \mathrm{~mm}$. Dental casts (University of Massachusetts) from Ranomafana (top to bottom): UM-ADCC 1408, 1407, 1212; Vatateza: UM-ADCC 1400, 1405, 1399; Andasivodihazo: UM-ADCC 1401, 1402, 1406.

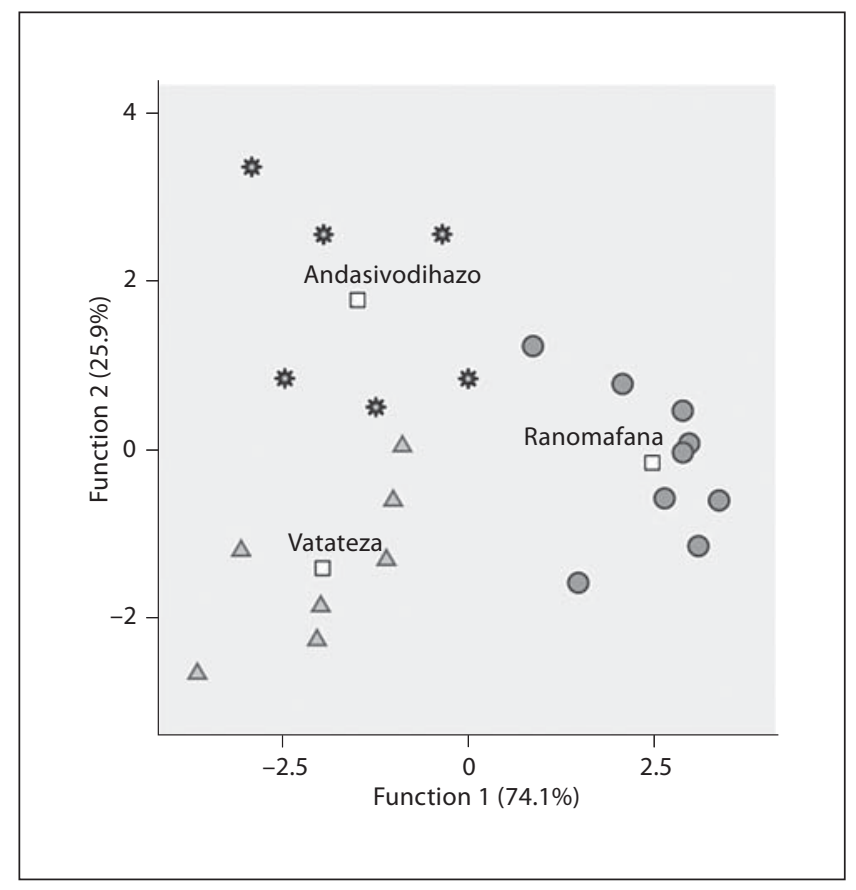

Fig. 6. DFA of dental variables: square root $\mathrm{M}_{2}$ 3-dimensional area, square root $\mathrm{M}_{2}$ 2-dimensional area, $\mathrm{M}_{2}$ 2-dimensional longitudinal crest length, $\mathrm{M}_{2} 3$-dimensional longitudinal crest length, $\mathrm{M}_{2}$ 2-dimensional transverse crest length and $\mathrm{M}_{2}$ 3-dimensional transverse crest length. 
Table 4. Mean occlusal measurements $\left(\mathrm{mm}\right.$ or $\mathrm{mm}^{2}$ ) of $\mathrm{M}_{2}$ s from living Cheirogaleus used in the DFA (means \pm SD)

\begin{tabular}{lllllll}
\hline & I & II & III & IV & V & VI \\
\hline Ranomafana (n=9) & $3.5 \pm 0.1$ & $3.0 \pm 0.1$ & $5.9 \pm 0.3$ & $6.8 \pm 0.3$ & $1.2 \pm 0.1$ & $1.4 \pm 0.2$ \\
Vatateza (n=7) & $3.3 \pm 0.2$ & $2.8 \pm 0.1$ & $5.0 \pm 0.5$ & $5.5 \pm 0.5$ & $0.9 \pm 0.2$ & $0.9 \pm 0.3$ \\
Andasivodihazo (n=6) & $3.1 \pm 0.2$ & $2.7 \pm 0.2$ & $5.5 \pm 0.5$ & $6.2 \pm 0.5$ & $0.9 \pm 0.1$ & $0.9 \pm 0.1$ \\
\hline
\end{tabular}

Variables: $\mathrm{I}$ = square root $\mathrm{M}_{2}$ 3-dimensional area; $\mathrm{II}=$ square root $\mathrm{M}_{2}$ 2-dimensional area; $\mathrm{III}=\mathrm{M}_{2}$ 2-dimensional longitudinal crest length; $\mathrm{IV}=\mathrm{M}_{2}$ 3-dimensional longitudinal crest length; $\mathrm{V}=\mathrm{M}_{2}$ 2-dimensional transverse crest length; $\mathrm{VI}=\mathrm{M}_{2}$ 3-dimensional transverse crest length.

Table 5. ANOVAs for lower dentition occlusal traits, with Tukey's post hoc tests of HSD for location pairs

\begin{tabular}{lclll}
\hline Variable & $\mathrm{p}$ values & $\mathrm{R}-\mathrm{A}$ & $\mathrm{R}-\mathrm{V}$ & $\mathrm{V}-\mathrm{A}$ \\
\hline Tooth row length $\left(\mathrm{P}_{4}-\mathrm{M}_{3}\right)$ & $<0.001$ & $* * *$ & $*$ & $\mathrm{NS}$ \\
Square root $\mathrm{M}_{2}$ 2-dimensional area & $<0.001$ & $* * *$ & $*$ & $*$ \\
Square root $\mathrm{M}_{2}$ 3-dimensional area & 0.003 & $* *$ & $\mathrm{NS}$ & $\mathrm{NS}$ \\
$\mathrm{M}_{2}$ 2-dimensional long. crest length & 0.002 & $\mathrm{NS}$ & $* *$ & $\mathrm{NS}$ \\
$\mathrm{M}_{2}$ 3-dimensional long. crest length & $<0.001$ & $*$ & $* * *$ & $*$ \\
$\mathrm{M}_{2}$ 2-dimensional transverse crest length & 0.001 & $* *$ & $* *$ & NS \\
$\mathrm{M}_{2}$ 3-dimensional transverse crest length & $<0.001$ & $* *$ & $* *$ & NS \\
\hline
\end{tabular}

$\mathrm{R}=$ Ranomafana; $\mathrm{A}=$ Andasivodihazo; $\mathrm{V}=$ Vatateza; long. $=$ longitudinal. ${ }^{*} \mathrm{p}<0.05,{ }^{* *} \mathrm{p}<$ $0.01,{ }^{* * *} \mathrm{p}<0.001 ; \mathrm{NS}=$ non-significant.

Table 6. Descriptive statistics for mandibular tooth row length $\left(\mathrm{P}_{4}-\mathrm{M}_{3} ; \mathrm{mm}\right)$, in Cheirogaleus from Tsinjoarivo (Vatateza and Andasivodihazo), Ranomafana (Talatakely) and museum specimens from other locations, with ANOVA

\begin{tabular}{llll}
\hline Sample & $\mathrm{n}$ & Mean & SD \\
\hline Talatakely & 9 & 12.76 & 0.24 \\
Vatateza & 7 & 12.26 & 0.35 \\
Andasivodihazo & 6 & 11.76 & 0.55 \\
C. sibreei & 1 & 11.30 & - \\
C. crossleyi & 3 & 12.78 & 0.56 \\
C. medius & 2 & 9.57 & 0.13 \\
\hline
\end{tabular}

ANOVA: $\mathrm{F}=25.41 ;$ d.f. $=5,22 ; \mathrm{p}<0.001$. 


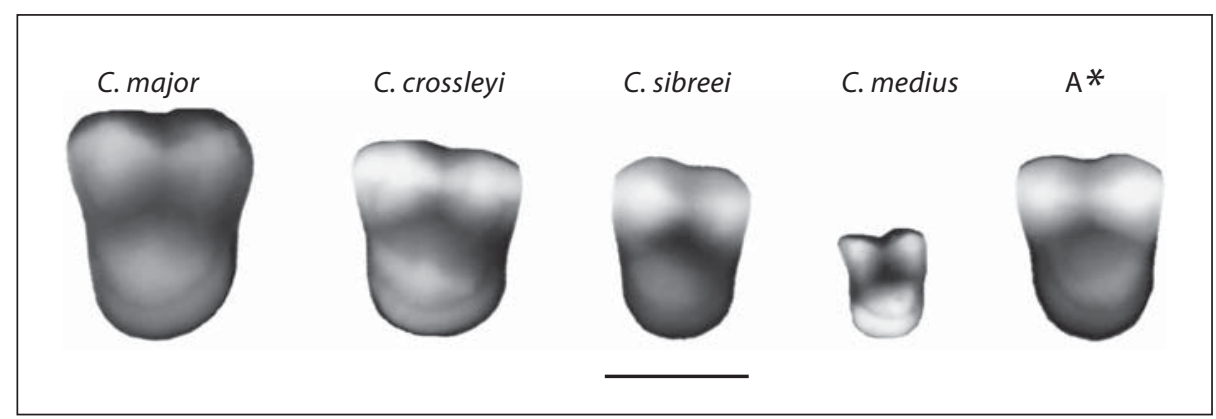

Fig. 7. DEMs of $\mathrm{M}^{2}$ from Andasivodihazo and museum specimens: Leiden (Naturalis), the British Museum (BMNH) and the University of Antananarivo (UADBA); scale bar $=3 \mathrm{~mm}$. From left to right: C. major Naturalis 1887:66f (left), C. crossleyi Naturalis 1887:66h (left), C. sibreei Naturalis 1887:66b (left), C. medius BMNH 48.165 (right), A* UADBA-TFFP-001 from Andasivodihazo (right).

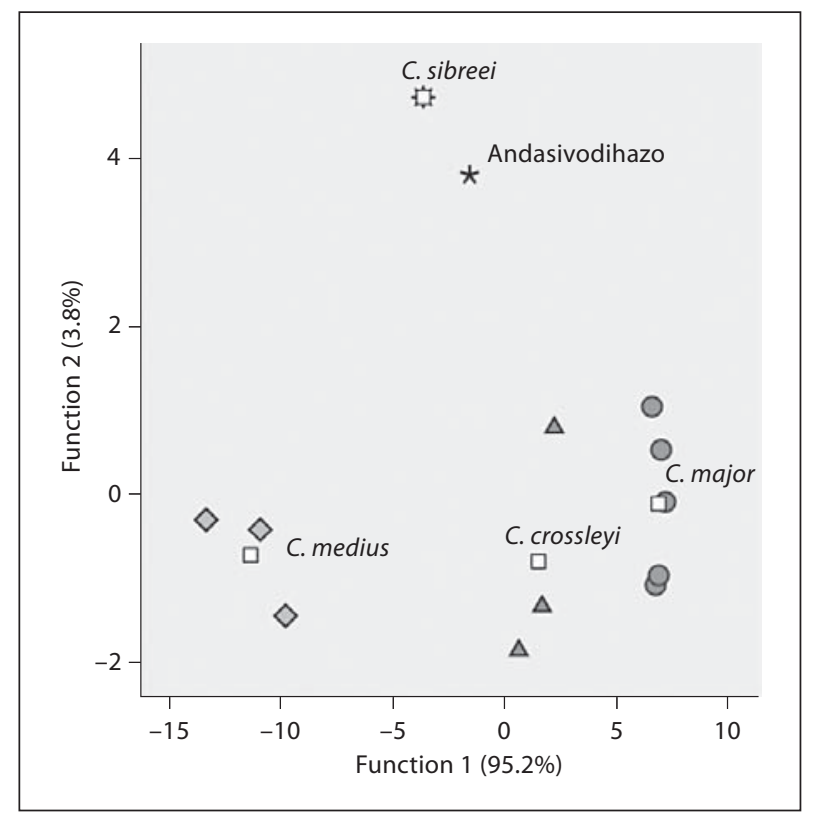

Fig. 8. DFA of $\mathrm{M}^{2}$ occlusal traits. Star = Tsinjoarivo individual (UADBA-TFFP-001); squares = group centroids.

Table 6 compares mandibular tooth row lengths $\left(\mathrm{P}_{4}-\mathrm{M}_{3}\right)$ of samples from RNP, Vatateza and Andasivodihazo, a museum specimen attributed by Groves [2000] to C. sibreei, and additional samples identified as C. crossleyi and C. medius using Groves' standards. The mean of Andasivodihazo individuals resembles that of $C$. sibreei from north-western Madagascar; both have a small $\mathrm{P}_{4}$. 
Table 7. Structure matrix of the DFA of $\mathrm{M}^{2}$ occlusal traits (first 2 functions)

\begin{tabular}{llc}
\hline Variables & Function 1 & Function 2 \\
\hline Square root 2-dimensional area & 0.490 & -0.001 \\
Square root 3-dimensional area & 0.323 & -0.134 \\
3-dimensional transverse crest length & 0.028 & 0.114 \\
2-dimensional longitudinal crest length & 0.176 & 0.065 \\
3-dimensional longitudinal crest length & 0.111 & -0.034 \\
2-dimensional transverse crest length & 0.045 & 0.166 \\
\hline
\end{tabular}

Table 8. Skeletal morphometrics of Cheirogaleus at Andasivodihazo (UADBA-TFFP-001) and other taxa $(\mathrm{mm})$

\begin{tabular}{lccccc}
\hline & Andasivodihazo & C. major & C. medius & C. crossleyi & C. sibreei \\
\hline Max. cranial length & & & & \\
Mean & $51.0(1)$ & $56.0(18)$ & $40.8(26)$ & $50.0(4)$ & $46.8(2)$ \\
SD & - & 2.4 & 1.4 & 2.2 & 1.0 \\
Min.-max. & - & $52.2-61.0$ & $38.2-43.3$ & $47.2-52.2$ & $46.1-47.5$ \\
Bizygomatic breadth & & & & \\
Mean & $34.1(1)$ & $36.2(17)$ & $26.9(10)$ & $30.8(4)$ & $30.9(2)$ \\
SD & - & 1.9 & 1.2 & 1.2 & 0.4 \\
Min.-max. & - & $32.0-39.8$ & $25.0-28.8$ & $29.1-32.0$ & $30.6-31.2$ \\
Prosthion-staphylion & & & & \\
Mean & $22.5(1)$ & $24.1(17)$ & $16.4(10)$ & $21.0(3)$ & $20.1(2)$ \\
SD & - & 1.0 & 0.7 & 0.7 & 1.3 \\
Min.-max. & - & $22.3-25.8$ & $15.2-17.5$ & $20.0-21.5$ & $19.2-21.0$ \\
Femur length & & & & - \\
Mean & $51.6(1)$ & $58.9(9)$ & $39.8(15)$ & - & - \\
SD & - & 1.5 & 1.5 & - & - \\
Min.-max. & - & $56.1-60.7$ & $37.4-42.3$ & - & - \\
Humerus length & & & & & - \\
Mean & $35.3(1)$ & $42.0(8)$ & $27.6(16)$ & - & - \\
SD & - & 1.7 & 1.3 & - & - \\
Min.-max. & - & $39.9-44.9$ & $25.2-30.3$ & - & \\
\hline
\end{tabular}

Figures in parentheses indicate numbers. Identity of comparative specimens and raw data are available from L.R.G. on request.

A comparison of second upper molars also highlights similarities between Andasivodihazo Cheirogaleus and north-western 'C. sibreei' (from Ampasindava Bay), though only 1 upper dentition from Andasivodihazo (UADBA-TFFP-001) and $1 C$. sibreei specimen were available for this analysis (fig. 7). An $\mathrm{M}^{2}$ dental trait DFA (treating the Andasivodihazo specimen as unknown) correctly classified $100 \%$ of the 
specimens $(\mathrm{n}=13$, fig. 8). Table 7 provides the correlations of the new functions with the original variables. The first function distinguished C. major (and to a lesser extent, $C$. crossleyi) from $C$. medius, mainly due to larger 2- and 3-dimensional areas and relatively longer longitudinal (but not transverse) crests. The Ampasindava $C$. sibreei and UADBA-TFFP-001 fell in the middle, close to C. crossleyi. Function 2 separated the Ampasindava C. sibreei and UADBA-TFFP-001 from all other individuals, largely due to long transverse crests relative to occlusal area. On this basis, the Andasivodihazo specimen was classified as C. sibreei; the Ampasindava Bay C. sibree $i$ and the Andasivodihazo specimen are quite similar in size and form, despite their geographic separation.

Finally, skeletal morphometrics are concordant with field morphometrics and dental analysis (table 8). Here, C. sibreei is represented by the holotype from Ankerimadinika and the specimen whose teeth we moulded from Ampasindava Bay. UADBA-TFFP-001 is smaller than C. major, larger than C. medius and similar in size to $C$. crossleyi and C. sibreei.

In summary, neither pelage nor morphometric and dental data support an inference of conspecificity for Cheirogaleus from the two sites at Tsinjoarivo. Rather, individuals from the continuous forest (Vatateza) resemble Ranomafana Cheirogaleus (despite their smaller size), while individuals from the fragment (Andasivodihazo) are smaller yet and resemble C. sibreei from Ampasindava Bay in pelage, mandibular tooth row length and upper second molar form. It also resembles the holotype of C. sibreei in pelage and in skull measurements.

\section{Discussion}

Our understanding of the true number of dwarf lemur species and their geographic distributions is in flux, and the status of Groves' revised species is currently under debate. For example, a brief lemur census along the Manambolo River in central western Madagascar [Thalmann and Rakotoarison, 1994] reported the presence of a Cheirogaleus sp. cf. major, a species thought to exclusively inhabit Madagascar's eastern forests. Recently, Hapke et al. [2005] described a C.-crossleyi-like morphotype in sympatry with C. major and C. medius at Fort Dauphin, a south-eastern location well outside the northern distribution reported for C. crossleyi [Groves, 2000]. Finally, Rasolofoson et al. [2007] reported several Cheirogaleus species (including C. sibreei) at Maroantsetra in north-east Madagascar (these attributions should be viewed as provisional as species were identified only via censusing).

A valid re-appraisal of Groves' taxa will require a concerted effort relating new data on phylogenetic relationships and range boundaries to Groves' holotype specimens. In this spirit, Groeneveld et al. [2008a, b] defended 3 Cheirogaleus clades (medius, major and crossleyi); Groves' other forms were nested within these 3. C. sibreei from Ampasindava Bay was found to belong, albeit as a large-bodied member, to the medius clade (as was C. adipicaudatus from southern Madagascar), and C. ravus nested within the major clade. No molecular analysis was conducted of the C. sibreei holotype from Ankeramadinika (east of Antananarivo). A single Cheirogaleus from Ranomafana was identified as C. crossleyi [Groeneveld et al., 2008b]. Further sampling from holotype specimens is warranted. 
Our data demonstrate at a minimum that the Cheirogaleus at Andasivodihazo and Vatateza are not conspecific; thus, a diversity greater than that previously inferred for Tsinjoarivo (i.e. C. major) must exist. Conservatively, the 2 Cheirogaleus species can be designated species 1 (Andasivodihazo) and species 2 (Vatateza). Less conservatively, we might infer that the species in the continuous forest (Vatateza) is conspecific with that at Ranomafana (likely C. crossleyi, see Groeneveld et al. [2008b]) and the species in the fragment is ' $\mathrm{C}$. sibreei'. It is clear that our population shares a number of morphometric traits with the few individuals that have been identified as C. sibreei. Several interpretations of these similarities are possible and can be posited as hypotheses, testable via genetic analysis.

First, our population may indeed belong to C. sibreei. In this case, its DNA must match that of the holotype from Ankeramadinika, and possibly specimens from Ampasindava. On the basis only of DNA from a specimen from Ampasindava (i.e. not the holotype), Groeneveld et al. [2008b] interpreted 'C. sibreei' as well embedded within the C. medius clade; however, Groeneveld et al. [2008a] also questioned the conspecificity of specimens previously identified as C. sibreei. Alternatively, if our population does not genetically match the holotype of $C$. sibreei, then the similarities we describe above can only be plesiomorphic or convergent, and a new species name must be proposed.

In either case, our discoveries have important taxonomic and potentially biogeographic implications. Currently, no living C. sibreei population is known to exist anywhere in Madagascar [Mittermeier et al., 2006]; if the Andasivodihazo population belongs to C. sibreei, it would represent the first and only known living population. If $C$. sibreei belongs to the $C$. medius clade, then this clade's distribution is extended into the central plateau (Ankeramadinika) and perhaps into the eastern rain forest (Tsinjoarivo) - i.e. effectively throughout Madagascar. Prior researchers identified living populations of $C$. medius in western, northern (including north-eastern) and southern (including south-eastern) Madagascar, but not in the east. If, on the other hand, the fragment population represents a new species, its significance for conservation, biogeographic and ecological research is obvious.

Future research should proceed in two directions. First, we need more concentrated field work to assess geographic distributions and habitat preferences of living Cheirogaleus populations. Second, we need genetic analyses including multiple individuals from both Tsinjoarivo sites. After ranges are better understood, ecological study could shed light on niche separation [Lahann, 2008]; for example, some Cheirogaleus species avoid forest edge habitats while others do not. Differences in microhabitat preference may explain the distributions of Cheirogaleus species at Tsinjoarivo; clearly, such knowledge would greatly aid not only in interpreting morphological differences, but also in establishing conservation policy. The collaborative research of Groeneveld et al. [2008a, b] is an excellent example of how molecular and morphological research can complement one another, but clearly we need more field research to decipher species' ecological and geographic limits, and thus to resolve questions concerning species boundaries and conservation priorities. 


\section{Acknowledgments}

We thank the government of Madagascar (especially ANGAP, and MINENVEFT) for research permissions. Research protocols were approved by the University of Massachusetts Institutional Animal Care and Use Committee. We acknowledge assistance from collaborators in the laboratory (Stephen King, Jukka Jernvall) and field (Edmond Razanadrakoto, Noel Rakotoniaina, Victor Rasendrinirina, Jean-Claude Rakotonirina), and curators at: Museum of Comparative Zoology, Cambridge, Mass., USA; British Museum (Natural History), London, UK; Field Museum of Natural History, Chicago, Ill., USA; Muséum National d'Histoire Naturelle, Paris, France, and the Naturalis Museum, Leiden, the Netherlands. Research was supported financially by the David J. Klingener Endowment (University of Massachusetts, Amherst), $\mathrm{MMBF} / \mathrm{CI}$ Primate Action Fund, the Rufford Foundation, Primate Conservation Inc. and Helsinki Biotechnology Institute (to M.B.B.), Margot Marsh Biodiversity Foundation and NSERC (to M.T.I.) and the National Science Foundation (to L.R.G.). Research was facilitated by ICTE (Patricia Wright), MICET (Benjamin Andriamihaja) and Centre Valbio (Anna Feistner, Jean Claude Razafimahaimodison, Aimée Razafiarimalala). Comments from Steven Goodman and three anonymous reviewers on an earlier draft of this manuscript are greatly appreciated.

\section{References}

Burney DA (1997). Theories and facts regarding Holocene environmental change before and after human colonization. In Natural Change and Human Impact in Madagascar (Goodman SM, Patterson BD, eds.), pp 75-89. Washington, Smithsonian Institution Press.

Drea CM, Weil A (2008). External genital morphology of the ring-tailed lemur (Lemur catta): females are naturally 'masculinized'. Journal of Morphology 269: 451-463.

Dufils J-M (2003). Remaining forest cover. In The Natural History of Madagascar (Goodman SM, Benstead JP, eds.), pp 88-96. Chicago, University of Chicago Press.

Godfrey LR, Jungers WL, Reed KE, Simons EL, Chatrath PS (1997). Subfossil lemurs: inferences about past and present communities in Madagascar. In Natural Change and Human Impact in Madagascar (Goodman SM, Patterson BD, eds.), pp 218-156. Washington, Smithsonian Institution Press.

Goodman SM, Rakotondravony D, Raherilalao MJ, Rakotomalala D, Raselimanana AP, Soarimalala V, Duplantier J-M, Duchemin J-B, Rafanomezantsoa J (2000a). Inventaire biologique de la forêt de Tsinjoarivo, Ambatolampy. Akon'ny Ala 27: 18-27.

Goodman SM, Rakotondravony D, Soarimalala V, Duchemin J-B, Duplantier J-M (2000b). Syntopic occurrence of Hemicentetes semispinosus and H. nigriceps (Lipotyphla: Tenrecidae) on the central highlands of Madagascar. Mammalia 64: 113-116.

Goodman SM, Schütz H (1999). Observations of lemurs in the forest east of Tsinjoarivo, Ambatolampy. Lemur News 4: 14-16.

Green GM, Sussman RW (1990). Deforestation history of the eastern rain forests of Madagascar from satellite images. Science 248: 212-215.

Groeneveld LF, Rasoloarison R, Kappeler PM (2008a). Morphometrics of the genus Cheirogaleus: what do museum and field specimens tell us about dwarf lemur diversity? In Species Delimitation, Phylogeography and Population Genetics of the Endemic Malagasy Dwarf Lemurs (Genus Cheirogaleus) (Groeneveld LF, ed.), pp 7-22. PhD thesis, Göttingen.

Groeneveld LF, Weisrock D, Rasoloarison R, Yoder AD, Kappeler PM (2008b). Species delimitation in endemic Malagasy dwarf lemurs (genus Cheirogaleus) based on mitochondrial and nuclear DNA. In Species Delimitation, Phylogeography and Population Genetics of the Endemic Malagasy Dwarf Lemurs (Genus Cheirogaleus) (Groeneveld LF, ed.), pp 23-45. PhD thesis, Göttingen.

Groves CP (2000). The genus Cheirogaleus: unrecognized biodiversity in dwarf lemurs. International Journal of Primatology 21: 943-962.

Hapke A, Fietz J, Nash SD, Rakotondravony D, Rakotosamimanana B, Ramanamanjato J-B, Randria GFN, Zischler H (2005). Biogeography of dwarf lemurs: genetic evidence for unexpected patterns in southeastern Madagascar. International Journal of Primatology 26: 873-900.

Irwin MT (2006). Ecological Impacts of Forest Fragmentation on Diademed Sifakas (Propithecus diadema) at Tsinjoarivo, Eastern Madagascar: Implications for Conservation in Fragmented Landscapes. PhD Thesis, Stony Brook University. 
Irwin MT, Samonds KE, Glander KE, Raharison J-L (2000). A census of the primate community of Tsinjoarivo (Ambatolampy), Madagascar, with observations of a previously undescribed sifaka, Propithecus sp., No 10. Unpublished Report to ANGAP, Antananarivo.

Jenkins PD, Carleton MD (2005). Charles Immanuel Forsyth Major's expedition to Madagascar, 1894 to 1896: beginnings of modern systematic study of the island's mammalian fauna. Journal of Natural History 39: 1799-1818.

Koechlin J, Guillaumet J-L, Morat P (1974). Flore et végétation de Madagascar. Vaduz, Gantner.

Lahann P (2008). Habitat utilization of three sympatric cheirogaleid lemur species in a littoral rain forest of southeastern Madagascar. International Journal of Primatology 29: 117-134.

Lowry PP II, Schatz GE, Phillipson PB (1997). The classification of natural and anthropogenic vegetation in Madagascar. In Natural Change and Human Impact in Madagascar (Goodman SM, Patterson BD, eds.), pp 93-123. Washington, Smithsonian Institution Press.

MacPhee RDE, Burney DA, Wells NA (1985). Early Holocene chronology and environment of Ampasambazimba, a Malagasy subfossil lemur site. International Journal of Primatology 6: 463-489.

Milne-Edwards A, Grandidier A (1875). Histoire physique, naturelle et politique de Madagascar. 9. Histoire naturelle des mammifères. Paris, Imprimerie Nationale.

Mittermeier RA, Konstant WR, Hawkins F, Louis EE, Langrand O, Ratsimbazafy J, Rasoloarison R, Ganzhorn JU, Rajaobelina S, Tattersall I, Meyers DM (2006). Lemurs of Madagascar, 2nd ed. Washington, Conservation International.

Ostner J, Heistermann M, Kappeler PM (2003). Intersexual dominance, masculinized genitals and prenatal steroids: comparative data from lemurid primates. Naturwissenschaften 90: 141-144.

Petter J-J, Albignac R, Rumpler Y (1977). Faune de Madagascar. 44. Mammifères lémuriens (Primates prosimiens). Paris, ORSTROM/CNRS.

Rakotondraparany F (1997). Inventaire faunistique de la forêt naturelle de Tsinjoarivo-Ambatolampy. Fasc 32. Antananarivo, GTZ/PDFIV.

Rand AL (1936). The distribution and habits of Madagascar birds. A summary of the field notes of the Mission Zoologique Franco-Anglo-Américaine à Madagascar. Bulletin of the American Museum of Natural History 72: 143-499.

Rasoloarison RM, Goodman SM, Ganzhorn JU (2000). Taxonomic revision of mouse lemurs (Microcebus) in the western portions of Madagascar. International Journal of Primatology 21: 963-1019.

Rasolofoson D, Rakotondratsimba G, Rakotonirainy O, Rakotozafy L, Ratsimbazafy J, Rabetafika L, Randrianarison R (2007). Influences des pressions anthropiques sur les lémuriens d'Anantaka, dans la partie est du plateau de Makira, Maroantsetra, Madagascar. Madagascar Conservation and Development 2: 21-27.

Tattersall I (2007). Madagascar's lemurs: cryptic diversity or taxonomic inflation? Evolutionary Anthropology 16: 12-23.

Thalmann U, Rakotoarison N (1994). Distribution of lemurs in central western Madagascar, with a regional distribution hypothesis. Folia Primatologica 63: 156-161.

Treatman-Clark K (2006). The Evolution of the Reproductive System in Strepsirhine Primates. PhD thesis, Stony Brook University. 